Faculdade de Ciências Econômicas UFRGS
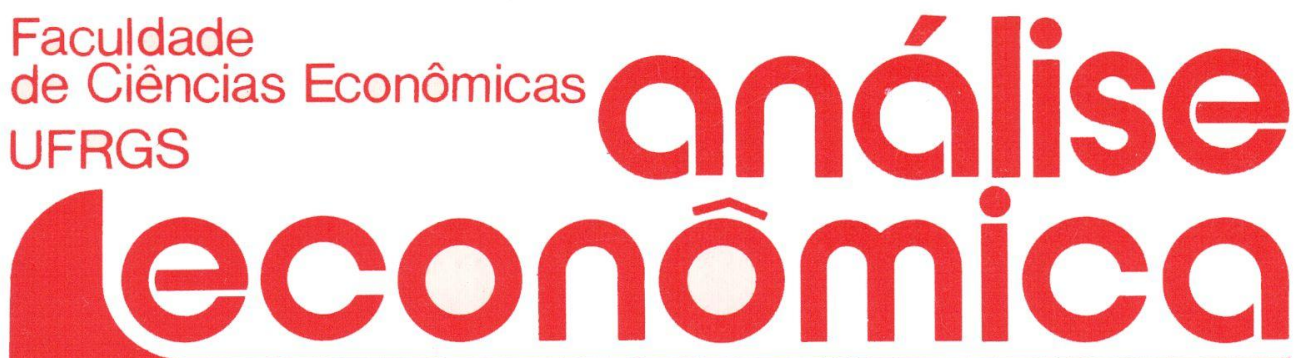

- A LINEAR MOdEL Of BALANCEd GROWTH Joanilio Rodolpho Teixeira Rodrigo Andrés de Souza Penaloza

- TEORIAS ESTRUTURALISTAS DA INFLAÇÃO

Roberto Camps Moraes

- PREÇOS EXTERNOS E EXPÓRTAÇÃO DE MANUFATURADOS Lauro Lobo Burle

- O DESENVOLVIMENTO SUECO Alfredo Marcolin Peringer

- DÉFICIT ENERGÉTICO Fabiano Augusto Nogueira Pinto

- RICARDO E O PROBLEMA SOCIAL Cezar Machado Mello

- UM SABER QUE NÃo SABE: INSTRUMENTO DE PREVISÃO Eleutério F.S. Prado

- SELEÇÃo dE PLANOS DE PRODUÇÃO PARA PEQUENOS PRODUTORES AGRICOLAS Juvir Luiz Mattuella

- PERSPECTIVAS da ECONOMIA do NORDESTE NA DÉCADA DE NOVENTA

Liana Maria da Frota Carleial

- CAIO PRADO JÚNIOR

Pedro Cezar Dutra Fonseca 
UNIVERSIDADE FEDERAL DO RIO GRANDE DO SUL Reitor. Prof. Tuiskon Dick

FACULDADE DE CIÊNCIAS ECONÔMICAS

Diretor: Prof. Walter Meucci Nique

CENTRO DE ESTUDOS E PESQUISAS ECONÔMICAS

Diretor: Reinaldo lgnácio Adams

DEPARTAMENTO DE CIÉNCIAS ECONÔMICAS

Chefe: Prof. Pedro Cezar Dutra Fonseca

CURSO DE PÓS-GRADUAÇÃO EM ECONOMIA

Coordenador: Prof. Nali de Jesus de Souza

CURSO DE PÓS-GRADUAÇĀO EM ECONOMIA RURAL

Coordenador. Prof. Atos Freitas Grawunder

CONSELHO EDITORIAL: Achyles Barcelos da Costa, Aray Miguel Feldens, Atos Freitas Grawunder, Carlos Augusto Crusius, Ernani Hickmann, João Rogério Sanson, Juvir Luiz Mattuella, Maria Imilda da Costa e Silva, Nali de Jesus de Souza, Nuno Renan Lopes de Figueiredo Pinto, Otília Beatriz Kroeff Carrion, Otto Guilherme Konzen, Paulo Alexandre Spohr, Pedro Cezar Dutra Fonseca, Reinaldo Ignacio Adams, Roberto Camps Moraes, Valter José Stülp, Yeda Rorato Crusius, David Garlow (Wharton Econometrics Forecasts Association, E.U.A.), Edgar Augusto Lanzer (UFSC), Eleutério F.S. Prado (USP), Fernando Holanda Barbosa (FGV/RJ), Gustavo Franco (PUC/RJ), Joaquim Pinto de Andrade (UnB), Juan H. Moldau (USP), Werner Baer (Univ. de Illinois, E.U.A.).

COMISSĀO EDITORIAL: Atos Freitas Grawunder, Pedro Cezar Dutra Fonseca, Reinaldo Ignacio Adams e Roberto Camps Moraes.

EDITOR: Nali de Jesus de Souza

SECRETARIA: Maria Ivone de Mello (normalização), Vanete Ricacheski (revisão de textos), Zélide Bregalda (Secretária).

FUNDADOR: Prof. Antônio Carlos Santos Rosa

Os materiais publicados na revista Análise Econômica são de exclusiva responsabilidade dos autores. É permitida a reprodução total ou parcial dos trabalhos, desde que seja citada a fonte.

Aceita-se permuta com revistas congêneres. Aceitam-se, também, livros para divulgação, elaboração de resenhas ou recensōes.

Toda correspondência, material para publicação, assinaturas e permutas devem ser dirigidos ao seguinte destinatário:

PROF. NALI DE JESUS DE SOUZA

Revista Análise Econômica

Av. João Pessoa, 52

90.040 - PORTO ALEGRE (RS), BRASIL

Telefone: (0512) 25-58-44 ramal 33

Fax: (0512) 25-5253 


\title{
O DESENVOLVIMENTO ECONÔMICO SUECO: O CAMINHO DA INTERVENÇÃO ESTATAL*
}

\author{
Alfredo Marcolin Peringer ${ }^{\star \star}$
}

\begin{abstract}
SINOPSE
Este artigo vale-se do modelo econômico adotado pela Suécia para mostrar que todo desenvolvimento apoiado no Estado, em detrimento da livre iniciativa, não é um desenvolvimento auto-sustentado, mas um desenvolvimento artificial. Cedo ou tarde tem de ser revertido, com grandes custos sociais. Estudou-se a origem, os estágios iniciais, a consolidação, o inicio da queda, o declínio e a diffcil situação atual do Estado intervencionista sueco. O estudo converge para o fato de que, inevitavelmente, o povo sueco vai ter de pagar um preço bem alto - queda da produção e desemprego - para trazer de volta a economia ao equilhbrio. E esse retorno só é viável, dado determinado custo, com a adoção de uma economia guiada pelas leis de mercado.
\end{abstract}

\section{ORIGEM DAS IDÉIAS INTERVENCIONISTAS SUECAS}

A Suécia foi um país pouco afetado pela Grande Depressão dos anos trinta. Em 1932, quando muitos países europeus enfrentavam grandes dificuldades econômicas, a economia sueca cresceu $7 \%$. Muitos habitantes que haviam deixado o país para a América nos anos 20 , pressionados pela depressão de 1919 a 1923, época em que o nivel de desemprego na Suécia subiu a $25 \%$ e os salários reais foram reduzidos

\footnotetext{
* O autor agradece ao Professor Nali Jesus de Souza não só pela valiosa troca de idéias, mas também pelas correçōes e pelas diversas sugestões que ele fez com relação ao formato e apresentação deste trabalho.

** Economista. Mestre em Finanças pela "Michigan State University".
}

ANÁLISE ECONÔMICA

ANO 8

№ 14 NOVEMBRO/90 p.51-67 
em cerca de $35 \%$, retornaram ao País nos anos trinta, a procura de meIhores dias diante da Grande Depressão sofrida pelos Estados Unidos.

É importante mencionar que a preocupação do mundo era com a queda do nivel da atividade econômica. Pouca importância tinha na época os desequilíbrios inflacionários. Era a depressão e não a inflação que atingia mais ou menos o mundo inteiro e os economistas procuravam soluções para os problemas da queda da produção e do emprego. Queriam também fórmulas para obter o crescimento auto-sustentado.

Foi com a intenção de não deixar cair o nivel de utilização da capacidade econômica sueca e desenvolver o País que o Partido Social Democrata, ao assumir o governo em 1932, chamou o então jovem economista sueco Gunnar Myrdal para trabalhar num "plano econômico" que abrisse um caminho em direção ao crescimento econômico do Pais.

Embora a Teoria Geral ainda não tivesse sido lançada, Myrdal deve ter sido influenciado por um artigo de Keynes, publicado em jornais em 1929, entitulado Can Lloyd George Do It?, que responsabilizava o baixo poder de compra salarial pelo desemprego e pela queda do nivel na atividade econômica. Myrdal foi mais keynesiano ainda ${ }^{1}$, advogando a expansão dos gastos governamentais nas situações depressivas, com formação de déficits fiscais; restrição dos gastos governamentais nos surtos expansivos, com formação de superávits fiscais, idéias básicas introduzidas mais tarde na Teoria Geral por Keynes (1936). A intenção era a de que os gastos governamentais viessem a desencadear um efeito "multiplicador" da renda nas situações depressivas de forma a estimular a atividade econômica. De outra parte, o desaquecimento dos gastos públicos, também serviria para desencadear um desestimulador progressivo nos "booms" ecoriomicos, desaquecendo a economia e fazendo com que ela retornasse ao equilibrio. A idéia não poderia ser mais atrativa para um governo de cunho socialista. $O$ Estado passaria a contar com um volume maior de renda gerada na economia e iria dispor dessa renda de acordo com regras ditadas pelo próprio governo, de alto efeito político.

Essas idéias, contudo, nẩo passavam de ultrajes à ciência econômica. Wicksell (1951), economista sueco e um dos principais mentores da "Escola Austríaca", sempre advogou o afastamento do Estado da economia. Na concepção austríaca, as empresas em dificuldades eco-

1 GUDIN (1976, p.148) informa que Myrdal tinha outra visão com relação aos salários. Diz que, em artigo publicado no New Republic, alerta o governo americano para persuadir os sindicatos operários a suspender por um a dois anos os aumentos salariais. 
nômicas não poderiam ser auxiliadas, pois a quebra das empresas em estado falimentar - fato que, inevitavelmente, ocorre nos estados depressivos, quando se deixa o mercado funcionar livremente - é extremamente necessário se obter um desenvolvimento equilibrado. Embora Lundberg (1985), economista da Escola Econômica de Estocolmo, acuse Wicksell de ter negligenciado os aspectos relativos às flutuações no emprego e na produção sueca nos anos vinte, a acusação não faz jus às obras de Wicksell. Por exemplo, The Critical Point in the Law of Decreasing Agricultural Productivity (Wicksell, 1916), ou On the Problem of Distribution (Wicksell, 1902), tratam da teoria da produção e da distribuição. Ademais, o seu livro Interest and Prices (Wicksell, 1965), apesar de tratar da relação entre a taxa de juros, a quantidade de dinheiro e o nivel geral de preços, não deixa de ser um tratado sobre os ciclos econômicos, se considerarmos a moeda como a principal causadora dos altos e baixos da economia, o que é uma grande verdade, ao menos quando se verificam desequilibrios acentuados.

Como Wicksell faleceu em 1926, o confronto direto das idéias de Myrdal deu-se com outros dois economistas suecos, Gustav Cassel e Eli Heckscher. Cassel (ver Wicksell, 1951) ponderava que o elevado dispêndio orçamentário governamental e seus déficits não iriam influenciar o crescimento da atividade econômica. Ocorreria apenas uma transferência da poupança do setor privado para o setor estatal com o conseqüente aumento dos gastos governamentais e queda dos gastos privados em consumo e investimento. Ponderava que a soma do maior gasto do governo, com o menor gasto do setor privado, daria um resultado zero. A economia sueca não seria influenciada em nada, a não ser, negativamente, na sua eficiência. Isso passou a denominar-se "efeito deslocamento" ("crowding out effect"). Cassel não levou em conta que o setor estatal carrega no seu cerne um germe desestimulador que ataca, mais cedo ou mais tarde, a atividade motora do estado e que o induz a produzir menos do que a atividade privada. O somatório, portanto, do "mais" do setor governamental, corn o "menos" do setor privado, vai sempre dar um grande "menos" na economia.

$\mathrm{O}$ ataque mais forte ainda às idéias de Myrdal veio de Heckscher, que estudou o comportamento dos gastos de diversos governos e viu que eles não baixavam, tanto nas depressões quanto nos surtos econômicos. ${ }^{2}$ Acreditava, portanto, que o governo do Partido Social Democrata, uma vez iniciada a expansão dos gastos estatais, não conseguiria 2 Ver Lundberg (1985). 
nem contê-los, nem estabilizá-los, mesmo nos surtos de expansão econômica. Os gastos seriam sempre progressivos. Isso se passou a denominar na literatura econômica de "efeito catraca" ("Ratchet effect"). A colocação de Heckscher é tão acertada que se poderia denominar de "Efeito Heckscher", em alusão ao seu descobridor. Tem-se comprovado, em quase todas as partes do mundo, a dificuldade estatal em baixar os gastos uma vez iniciados. Sempre que a atividade estatal passa a ser usada em substituição às normas do mercado livre, há uma forte tendência de essa atividade aumentar progressivamente.

O governo do Partido Social Democrata, mesmo se não tivesse tido embasamento econômico para as suas teses de manter maior participação do estado na economia, teria inventado um motivo, como meio de aumentar o seu poder. Por isso, as idéias de Myrdal foram aceitas sem restrições.

\section{OS ESTÁGIOS INICIAIS DO MODELO INTERVENCIONISTA SUECO}

Diferente do que se esperava, contudo, a política econômica keynesiana, desenvolvida por Gunnar Myrdal, não desempenhou papel importante nos anos trinta e nos anos quarenta. Ao contrário, o governo Social Democrata, em vez de estimular a demanda, distribuindo grandes aumentos salariais, conforme pediam alguns economistas da época, passou a estimular a oferta, criando incentivos aos investimentos do setor privado. Foi reduzido, por exemplo, os impostos sobre os lucros. As empresas podiam abater dos lucros os investimentos realizados em bens de capital. Criou-se, ademais, um sistema que incentivava as empresas a investir nas situações de desaquecimento econômico, justamente para evitar a queda de produção e o desernprego nesses periodos.

Um dos principais objetivos estabelecidos pelos sociais democratas era manter o crescimento econômico, com estabilidade nos preços e no emprego. Muitos fatores contribuíram para que esse objetivo fosse alcançado. Entre eles podemos destacar:

a) - a redução de impostos e o aumento dos incentivos, que abriram caminho para o desenvolvimento das indústrias suecas;

b) - a desvalorização da coroa sueca em setembro de 1931 e a manutenção dessa desvalorização na década. Isso deu poder de competitividade às indústrias exportadoras suecas que se 
puderam desenvolver interna e externamente. Aliás, o setor exportador sueco sempre foi o carro chefe de seu desenvolvimento econômico;

c) - a manutenção de uma política monetária dentro das possibilidades de crescimento da atividade econômica sueca que manteve a taxa de juros baixa, ao redor de 3\% ao ano, dandó condições ao desenvolvimento econômico, principalmente do setor exportador e do setor habitacional.

A Suécia experimentou razoável crescimento econômico nos anos trinta, com preços estabilizados, exceto em 1936-7, no qual se verificou aumento no custo de vida de $4 \%$. Baixo para os padrões atuais da América Latina, mas altos para os padrões europeus da época, considerando que muitos países experimentavam periodos grandes de queda de preços.

Além do mais, o crescimento econômico proporcionava ganhos de produtividade que podiam ser transformados em aumentos reais de salários aos trabalhadores. Os trabalhadores ganharam, de fato, aumentos salariais na década, em percentuais, entretanto, nunca superiores ao crescimento da produtividade empresarial. Embora o governo social democrata tenha permitido a expansáo do sindicalismo, sendo possivel o desenvolvimento da Organização Central dos Trabalhadores (LO), houve, na década, uma convivência pacífica entre trabalhadores e empregadores, talvez pelas boas condições salariais proporcionadas pelo crescimento econômico.

Nessa época, contudo, havia intensa crítica ao aumento dos impostos. Gustav Cassel, em 1937, dizia que o governo sueco tinha atingido os limites de taxação suportável pela sociedade. De acordo com dados de Lundberg (1985), o nivel de impostos se encontrava ao redor de $15 \%$ do PIB sueco. Parece que se concretizavam, ademais, as previsões de Heckscher (efeito catraca): o governo sueco teria grandes problemas não só para reduzir os seus gastos, como para fazê-los parar de crescer. Os dispêndios governamentais dobraram do início ao final da década de trinta.

A década de quarenta foi positiva para a Suécia. Como era considerada um pais neutro, foi pouco afetada pelas duas Grandes Guerras e, com isso, pôde continuar o seu crescimento econômico. Os anos que se seguiram, após a guerra dos anos quarenta, foram de calmarias nas relações entre capital e trabalho. Embora alguns setores radicais do Partido Social Democrata exigissem medidas mais drásticas na economia, 
com pedidos até de guinadas ao socialismo completo, os moderados do partido se mantiveram vitoriosos.

Uma das reivindicações da classe trabalhadora era a de maior igualdade de renda entre os salários. Gunnar Myrdal de novo no comando dos "planos" econômicos, defendia, em 1944, uma ação maior e mais seletiva do governo no setor privado, com a intenção de proporcionar maior eficiência às empresas. Anunciava-se que, no periodo de guerra, teria havido descontrole dos investimentos privados e desequilíbrios estruturais que precisavam ser gerenciados pelo setor público para que se pudesse trazê-los ao equilíbrio. Entretanto, em vez de Myrdal procurar o remédio correto, receitava mais veneno. Pressionava para aumentar os impostos e dar maior participação do Estado na atividade econômica. Defendia o controle dos juros, de forma a mantê-los baixos e a viabilizar projetos inviáveis.

Discutia-se, na época, uma espécie de curva de Phillips. Acreditava-se em "trade-off" entre o nivel de desemprego e a inflação, pensando-se que alguns pontos a mais na inflação iriam melhorar, consistentemente, o nivel de emprego do País. Apesar de muitos economistas suecos não acreditarem nas possibilidades de se minimizar o desemprego à custa de alguns pontos na inflação, o Pais tinha uma meta: minimizar o desemprego a qualquer preço, para evitar as tensões sociais. Quando Bertil Ohlin, em 1949, informou que 5\% de desemprego era uma taxa razoável, recebeu intensa crítica de todos os lados, principalmente dos economistas sindicais, que advogavam uma taxa de $2 \%$ (Lundberg, 1985).

Em 1948, junto com o crescimento da economia mundial, proliferavam os adeptos da economia keynesiana. Alguns economistas julgavam que a inflação não era provocada pelo aumento monetário e sim pelos custos. Com isso, as metas de estabilidade nos preços desviavam-se dos agregados monetários para as políticas de renda. Exigia-se maior controle "seletivo" governamental dos preços e dos salários. Nesse ano, houve eleição e o Partido Liberal, de oposição ao governo, conseguiu reduzir consideravelmente o poder mantido pelo Partido Social Democrata. Em 1949, houve nova desvalorização da coroa sueca. A moeda sueca havia se valorizado com a inflação ocorrida em 1946. A desvalorização pavimentou o caminho para um novo surto desenvolvimentista da indústria exportadora do país. 


\section{A CONSOLIDAÇÃO E O INÍCIO DA QUEDA DO ESTADO INTERVENCIONISTA SUECO}

Nos anos cinqüenta, a economia sueca cresceu em média, 3,5\% ao ano, com ganhos anuais de produtividade ao redor de 1,5\%. Essa boa performance, entretanto, foi devida ao enorme crescimento do setor público. Em 1951, dois economistas sindicais - Rodolf Meidner e Gósta Rehn - começaram a aparecer nos noticiários em substituição a Gunnar Myrdal. Lançaram um movimento em defesa do "Pleno Emprego" ("The Trade Union Moviment and Full Employment"), hoje conhecido como modelo de Rehn-Meidner. A intenção deles era obter pleno emprego e fazer com que houvesse uma melhor distribuição de renda entre a população sueca. Era o início de um forte movimento em direção ao estatismo. Iniciou-se pelo ataque aos lucros empresariais. Pregavam a redução dos lucros pelas taxações indiretas das empresas e pelos aumentos dos salários. Como esperavam que muitas empresas viessem encontrar dificuldades financeiras, planejavam, com os recursos arrecadados, subsidiar as empresas marginais, impedindo que elas fechassem as portas, maneira de possibilitar nelas a manutenção do emprego.

Embutido também no modelo dos economistas sindicais suecos encontrava-se a idéia de transferir renda do setor privado para o setor público, aumentando o poder estatal na esfera econômica, de sorte a dar ao governo o poder de fazer a sua política "seletiva" de auxilio às empresas em dificuldades e aos trabalhadores desempregados. Como os impostos diretos sobre os lucros não eram suficientes para satisfazer a ambição da esfera estatal, passou-se também a criar impostos na foIha de pagamento dos trabalhadores. A desinformação econômica cegava tanto, que não permitia ao governo socialista ver que os recursos de impostos sobre a folha de pagamento não saíam dos empresários, mas dos próprios trabalhadores. Tiravam destes de um lado e distribuiam de outro. Não, porém, sem antes ficar com uma grande parcela dos recursos. Embora almejasse subsidiar as empresas em dificuldades financeiras, o modelo trazia uma penalidade muito grande para aquelas com mão-de-obra intensiva, justamente as mais necessitadas, com a criação da "Política Solidária de Salário". Pretendia-se, com essa política, dar igualdade salarial para o mesmo tipo de trabalho, não importando onde ele fosse exercido.

Nos anos sessenta o crescimento econômico sueco foi ainda maior do que o dos anos cinqüenta: 4,5\% ao ano. Entre 1965 e 1970, a 
produção industrial cresceu $5,1 \%$ ao ano, liderada pelo carro chefe do setor industrial, o setor exportador. Os ganhos de produtividade alcançaram 6,9\% ao ano, graças à possibilidade de se transferir mão-de-obra do setor industrial para o setor púbiico, em cerca de 1,8\% ao ano. $O$ setor governamental nunca cresceu tanto. Nele o emprego cresceu $6,1 \%$ entre 1965 e 1970. Em 1965, o governo respondia por 44\% do total do emprego. Em 1970, esse percentual passou para $57 \%$. Tendo presente os trabalhos de A.W. Phillips (1958), o governo apostava em gastos crescentes em educação, treinamento e informação para dar maior flexibilidade e maior mobilidade à mão-de-obra, maneira que julgava ser a mais eficaz para reduzir o "trade-off" entre inflação e desemprego. Esperava, com os programas de treinamento, transferir empregados das empresas com menores condições financeiras e com menores ganhos de produtividade, para aquelas com melhores condições financeiras e com maiores ganhos de produtividade.

Como era de se esperar, os impostos cresceram 15\% para as rendas altas (Skr 120 mil anuais) e 35\% para as rendas mais baixas (Skr 30 mil). Houve, ademais, um vigoroso aumento dos gastos com a previdência social para amparar velhos, doentes e desempregados. Era o "Welfare State" que se expandia.

\section{O DECLÍNIO DO MODELO INTERVENCIONISTA SUECO}

Nos anos setenta, o crescimento econômico caiu para $1,75 \%$ ao ano. Apesar dos modelos dos economistas sindicais, que exigiam maior participação estatal, o governo socialista conseguia reprimir muitas exigências. Por isso, o Governo socialista sueco ainda não tinha chegado ao limite extremo dos gastos. O nivel de emprego no setor público, porém, já tinha ultrapassado os limites do bom senso. Enfocamos que, enquanto o setor público empregava direta e indiretamente $44 \%$ da mão-de-obra sueca em 1965, em 1970 o percentual aumentou para 57\% e, em 1980, por incrivel que possa parecer, o total de pessoas constantes da folha de pagamento do setor público (diretamente empregados, pensionistas, doentes, etc.) representava $84 \%$ da mão-de-obra empregada na economia sueca, conforme dados do seu Ministério da Economia.

O Partido Social Democrata que, até então, conseguia manter a harmonia entre os sindicatos dos empregados e dos empregadores, agindo de forma a impedir abusos ras reivindicações salariais, perdeu a 
maioria no Congresso em 1973 e já não conseguia o dominio do consenso. A política salarial solidária levou à redução da diferença média entre um empregado especializado e um não-especializado de $54 \%$ nos anos sessenta, para $25 \%$ nos anos oitenta. Atingia o que eles pretendiam - igualdade de renda - mas afetava o estímulo ao desenvolvimento educacional e ao treinamento humano, fundamental numa economia desenvolvida. Os pais perdiam o interesse na educação dos filhos, uma vez que, com treinamento ou sem ele, os ganhos salariais seriam praticamente os mesmos.

Entre 1970 e 1974, a produção industrial ainda cresceu 3,5\% ao ano. O setor industrial conseguiu, também, aumento anual na produtividade de $5,3 \%$, graças à contínua transferência de mão-de-obra ao setor público, em percentuais de $1,8 \%$ ao ano, no período.

Perdendo a maioria do Congresso para os não-socialistas em 1973, o Partido Social Democrata veio, finalmente, a perder o governo em 1976. Ficou no poder, entretanto, 44 anos. O Partido Social Democrata cometeu muitos erros no governo, mas sempre seguiu critérios econômicos mais ou menos coerentes. O partido não-comunista, que assumia o poder, não mais obedecia, porém, a critério econômico algum. Os erros foram tantos que, entre 1974 e 1981, a produção industrial caiu $1,0 \%$ ao ano. Só conseguiu obter acréscimo na produtividade, em razão da demissão de $2,6 \%$ de sua mão-de-obra que foi, novamente, encontrar abrigo no setor estatal. Os projetos do setor público foram expandidos. $O$ crescimento estatal foi tão vigoroso que o fundo de pensão governamental, criado ainda pelo governo socialista, alcançou $50 \%$ do PNB sueco no final dos anos setenta. Os socialistas, quando se encontravam no poder, deixavam, ao menos, as empresas agir dentro das regras do mercado. Os não-socialistas passaram a exercer um controle governamental maior do que os socialistas. Aumentaram os subsidios discricionários e as transferências de verbas às empresas que julgavam merecedoras de auxílio. $O$ excesso de gasto estatal fez com que o consumo se mantivesse alto, apesar da queda da produção industrial. $O$ imposto de renda baixou, na década, $2 \%$ para as rendas de Skr 30 mil anuais, mas teve um salto de $26 \%$ para as rendas de Skr 120 mil. Como se poderia esperar, o Estado já não conseguia financiar os gastos apenas com os impostos e com os empréstimos. O pior de todos os impostos, o inflacionário, teve de ser acionado. Apesar de o crescimento econômico ter caído de 3,5\% ao ano, na década de sessenta, para 1,75\% na de setenta, o consumo governamental manteve-se em 3,5\% ao ano. 
A inflação na Suécia vinha se mantendo ao redor da média dos países da OCDE. As necessidades de financiamento, entretanto, faziam com que o governo sueco ultrapassasse a média dos países da OCDE. Em 1980 , a inflação atingiu o pico de $14 \%$, incrivelmente alta para os padrōes europeus. $E$ a inflação acirrava ainda mais as desavenças entre capital e trabalho. Em 1980, o custo da mão-de-obra era $3 \%$ maior do que a média dos países da Organização de Cooperação e Desenvolvimento Econômico (OCDE). Em 1989, aumentou para 10\%.

A mão-de-obra pressionava cada vez mais por melhores salários. Como de 70 a $80 \%$ das vendas das grandes empresas eram feitas no exterior e o setor exportador respondesse por $27,8 \%$ do PNB sueco, os aumentos salariais tiravam o poder de competitividade da economia sueca. Por isso, de 1970 a 1981, a Suécia experimentou um declínio de $15 \%$ em sua participação das exportações industriais em relação aos paises da OCDE.

\section{A DIFÍCIL SITUAÇÃO DOS ANOS OITENTA DO ESTADO INTERVENCIONISTA SUECO}

A primeira coisa que os Sociais Democratas fizeram ao reassumir o governo em 1982 foi desvalorizar a coroa sueca em 16\%, justamente para aumentar a competitividade externa das indústrias suecas. Muitos sabiam, porém, que a desvalorização não era eficaz para combater os problemas estruturais suecos. Aliás, sem que a Suécia mude a estrutura do mercado de trabalho e do setor público, não vai sair da difícil situação em que se encontra. O novo governo tem-se preocupado com a redução dos gastos governamentais. Conseguiu reduzir o déficit público, de $13 \%$ do PNB sueco em 1982, para $1 \%$ em 1989. Isso foi, contudo, mais pelo aumento das receitas do que pela redução dos gastos. $E$ como os gastos públicos não conseguem ser mais financiados pelos impostos e pelo crédito, tem-se apelado para os recursos via emissōes monetárias. E a situação tende a piorar. A inflação chegou a casa dos dois digitos e parece que não vai parar de subir. As greves por maiores salários têm sido uma constante na sociedade sueca. $O$ governo não tem mais de onde tirar recursos para dar emprego e continuar a sua política expansiva de gastos públicos e de manutenção de pleno emprego. E o povo não abre mão das mordomias estatais. Para dar uma idéia da caótica situação em que se encontra a economia sueca no ano de 1990, citamos os seguintes pontos: 
a) - o salário anual de Skr 160,000 (em torno de vinte e seis mil dólares) paga um imposto marginal de $60 \%$. Acrescentandose, porém, $43 \%$ de imposto sobre a folha de pagamento e $23,5 \%$ sobre o valor-adicionado, o trabalhador paga $80 \%$ sobre uma hora a mais trabalhada o que é um grande desestímulo ao trabalho e ao progresso econômico (um médico sueco trabalha cerca da metade do tempo $(1.600 \mathrm{~h} / \mathrm{ano})$ de um médico americano ( $2.800 \mathrm{~h} / \mathrm{ano})$;

b) - a diferença salarial de $1 \mathrm{~m}$ trabalhador profissional especializado (um professor universitário, por exemplo) e um não-especializado (operário de limpeza da universidade), não pode ser maior do que $25 \%$ (o que desestimula a especialização);

c) - Embora seja impossivel se ficar rico com o trabalho suado, o sistema premia aqueles que trabalham no mercado de capitais. Há possibilidade de evasão dos lucros de diversas maneiras, o que faz com que a capital da Suécia, Estocolmo, tenha mais automóveis Porsche por habitante do que qualquer cidade do mundo;

d) - O governo planeja um corte de $20 \%$ nos gastos públicos. Esse corte, contudo, deve recair nos projetos de investimentos e não nos de custeio o que vai levar a frangalhos a já esfarrapada infra-estrutura de serviços públicos da Suécia;

e) - O Partido Social Democrata quer dinamizar alguns serviços públicos, como o de saúde, permitindo que o setor privado concorra com o setor público nesse campo, mas encontra uma forte resistência dos radicais do partido.

O maior problema do "Welfare State" sueco, contudo, encontra-se no mercado de trabalho e na sua estrutura de relacionamento com o capital. Para dar uma idéia dos benefícios conseguidos para os trabaIhadores, apresentamos os seguintes pontos:

a) - diariamente, em cada empresa, um em cada quatro empregados estão ausentes (10\% por "doenças", 15\% cuidando dos filhos, estudando ou afastado do trabalho por alguns dos 101 motivos que the são permitidos por lei faltar);

b) - nos últimos 50 anos a força de trabalho sueca aumentou $30 \%$ e o número de horas trabalhadas foi reduzido em $15 \%$;

c) - ao nascimento de cada criança, o pai ou a mâe têrn o direito de ficar 15 meses em casa, que podern ser divididos entre 
eles, para cuidar do filho, com tudo pago. Mas os pais também têm o direito de ficar em casa por mais 60 dias ao ano, com tudo pago, para cuidar dos filhos em caso de doenças, até que eles completem a idade de 12 anos. Como não precisam apresentar atestado médico ou outra comprovação, os fithos sempre "adoecem", o que equivale a mais dois meses de férias anuais durante 12 anos;

d) - para receber os benefícios da previdência, é necessário apenas que o empregado (ou desempregado) deixe um recado numa secretária eletrônica instalada para essa finalidade e esperar o dinheiro em casa. Muitos recebem os beneficios, mas se encontram trabalhando em alguma outra empresa e recebendo normalmente por ela. Há um projeto para que as empresas, em lugar do governo, venham a pagar as duas primeiras semanas de licença do empregado. Para muitos políticos, isso eliminaria as fraudes. Dificilmente, porém, deve ser aprovado;

e) - o trabalhador também pode faltar cinco dias seguidos ao trabalho, também sem comprovação de atestado médico, por "doença", e sem que the seja deduzido nenhum centavo do seu salário (não há limite do número de faltas dessa espé cie);

f) - as faltas acima criaram um paradoxo para a Suécia: tem uma população com uma das maiores expectativas de vida do mundo, mas é uma das mais "doentes".

Para piorar a situação das indústrias suecas, que nunca sabem com quantos empregados vão poder contar a cada dia, há mais dois grandes problemas de iguais dimensōes aos trabalhistas: (1) a Suécia tem um prazo até o ano 2010 para fechar os seus 12 reatores nucleares. Os dois primeiros têm o prazo para fechar até 1995-96. O Governo não leva em conta que eles são responsáveis por cerca de $50 \%$ das fontes de energia daquele país; (2) a Suécia quer permanecer fora da Comunidade Econômica Européia, mas pensa que vai continuar com os beneficios de ser um dos seus parceiros.

Isso tem levado muitas empresas a rever os seus esquemas de investimento, preferindo investir no exterior do que investir na Suécia, onde encontram uma série de problemas, tais como:

a) alto custo de uma mão-de-obra "ausente";

b) a expectativa inflacionária para o ano de 1990 é de 10,8\%; 
c) A insatisfação social é grande na classe média; as greves são freqüentes, esperando-se maior custo da mão-de-obra e maior perda de competitividade;

d) A produção industrial caiu 3\% no primeiro semestre de 1990;

e) O aumento dos preços do petróleo e a queda nas exportações, vão elevar o déficit em conta corrente (a previsão é de Skr 34 bilhões este ano e Skr 44 bilhões em 1991);

f) O setor público não consegue mais se financiar através do aumento dos impostos e dos empréstimos e tem de apelar para o financiamento inflacionário. No curto prazo, os recursos, via inflação, permitem manter um volume de empregos artificiais no setor público. No longo prazo, contudo, esses empregos têm de ser desativados, quando, então, o desemprego se agrava.

\section{RESUMO E CONCLUSÕES}

O modelo de desenvolvimento econômico sueco foi baseado inicialmente nas idéias e Myrdal. Este, seguindo Keynes, atribuía as causas dos ciclos de expansão e de contração da atividade econômica às variaçóes no poder de cọmpra dos salários. Pregava, entre outras coisas: (1) o aumento dos gastos públicos, como meio de compensar a queda na atividade produtiva; (2) a contração dos gastos públicos, como meio de compensar os ciclos de expansão econômica. Os economistas sindicais, Rodolf Meidner e Cósta Rehn, foram os responsáveis: (1) pelo modelo de "pleno emprego" (que sobreviveu devido ao elevado aumento do emprego no setor governamental); (2) pela Política Solidária dos Salários (que fez com que a diferença entre a mão-de-obra especializada e a não-especializada fosse reduzida de $54 \%$ na década de sessenta, para $25 \%$ no ano de 1990 , e trouxesse grande desestímulo à capacitação profissional).

A política de Myrdal, contudo, pouca influência teve nas décadas de trinta e de quarenta. Em vez de incentivar a demanda, conforme pregava Myrdal, distribuindo grandes aumentos salariais, o governo Social Democrata estimulou a oferta, criando vários incentivos ao setor privado na promoção do crescimento econômico. Exemplo disso foi a possibilidade de poder abater dos lucros parte dos investimentos em bens de capital; foi a desvalorização da coroa sueca, de forma a promover as indústrias exportadoras; a elaboração de uma política monetária coerente 
com o crescimento do produto, como meio de possibilitar juros baixos à economia sueca, etc.

As décadas de cinqüenta e de sessenta foram os anos de ouro da economia sueca. $O$ crescimento foi artificial, entretanto, considerando que só foi possivel devido ao elevado crescimento estatal, financiado com poupanças compulsórias do setor privado. Os impostos sobre a sociedade cresceram além das possibilidades normais de aumento da carga tributária. A Política Solidária dos Salários abateu o ânimo dos trabalhadores.

$\mathrm{Na}$ década de setenta, a economia sueca começou a sentir os efeitos da exaustão dos recursos privados. Acabou a harmonia existente entre sindicatos dos trabalhadores e dos empregados. As pressōes politicas conduziram à criação de um vigoroso fundo de pensão social, que atingiu $50 \%$ do PNB sueco no final da década de setenta. A inflação passava a ser uma fonte adicional de recursos do governo que não conseguia se financiar mais só com impostos e empréstimos.

O estudo das teses de Wicksell (cálculo subjetivo), de Cassel ("efeito deslocamento"), de Heckscher ("efeito catraca") e de Laffer ("Curva de Laffer"), em conjunto e em separado, tem demonstrado que esses conceitos são de extrema exatidão para se fazer previsões a respeito dos eventos econômicos. Assim, pode-se dizer que é impossivel se manter a eficácia na atividade pública, em qualquer parte do mundo, tendo em conta que:

a) a atividade pública não tem a flexibilidade e o dinamismo para se obter o inter-relacionamento e a mobilidade necessários para se chegar ao verdadeiro cálculo econômico subjetivo;

b) não há como se evitar que haja o "efeito deslocamento" do setor privado pelo setor público, ao se expandir desmesuradamente as atividades estatais na economia;

c) uma vez iniciado o processo de gastos públicos, o governo não tem mais o domínio de parar de gastar quando bem assim 0 desejar. Ao contrário, há um "efeito catraca" que o impele a aumentar esses gastos cada vez mais;

d) pelo "efeito Laffer", o governo, cedo ou tarde, passa a ter de financiar o aumento dos gastos com aumento do endividamento - até levar à completa desestrutura financeira do estado - e, depois, à inflação.

Stuart (1981) concluiu que $75 \%$ do declínio sueco, em 1970, é explicado pelo aumento dos impostos. A economia sueca, contudo, ainda 
pode recorrer aos financiamentos inflacionários como forma de adiar a necessária organização de sua economia. Esse artifício, porém, vai fazer com que os seus problemas se agravem no futuro. A decisão correta seria reverter drasticamente a função estatal na economia e, por exemplo:

a) - minimizar a esfera de atuação do setor público em todos os setores da economia sueca;

b) - eliminar os subsidios e deixar que o mercado decida quais as empresas que deverão permanecer em atividade operacional;

c) - deixar o setor privado concorrer com o setor estatal em todos os setores, principalmente nos de saúde e de educação;

d) - iniciar um processo de privatização das empresas públicas;

e) - abandonar, em etapas, a patronagem existente no mercado de trabalho, até que; finalmente, empregados e trabalhadores resolvam as suas questões trabalhistas.

O estilo intervencionista da economia sueca criou um sistema estrutural de produção baseado fortemente no Estado. Com isso, pode-se prever que os custos sociais da mudança (transferência da poupança do setor público, para o setor privado) serão grandes e demorados. Esses custos serão na forma de queda da produção e do emprego. Não é de se estranhar se a queda da produção e do emprego arraste-se por mais de uma década.

\section{BIBLIOGRAFIA}

CASSEL, Gustav. The Theory os Social Economy. 2.ed. 1918. CENTRAL BUREAU OF STATISTICS. Statistisha Meddelanden, Stockholm, 1982.

. National Accounts, Stockholm, 1983.

GUDIN, Eugênio. Principios de Economia Monetária. Rio de Janeiro, Ed. AGIR, 1976 v.2.

JAKOBSSON, Ulf. Economic Growth in Sweden. World Economic Growth. San Francisco. In: Arnold C. Haberger. ICC PRESS, 1984, p.59-94.

KEYNES, John Maynard. The General Theory of Employment, Interest, and Money. New York. Ed. A Harbinger Book, 1964.

LAFFER, Arthur. The New Economics: A Debate. Economic Impact. Supply-Side Economics. International Communication AgencyUSA, N.35. 
LUNDBERG, Erik. The Rise and Fall of The Swedish Model. Journal Economic of Literature, v.23, p.1-36, Mar. 1985.

MYRDAL, Gunnar. Monetary Equilibrium. In: Bryce e Stopler, New York, 1939.

versity Press, 1955.

NATIONAL INSTITUTE OF ECONOMIC RESEARCH. The Swedish Economy, 1983, 1984. Stockholm, 1983, 1984.

PERINGER, Alfredo Marcolin. Monetarismo vs Keynesianismo vs Estruturalismo: Inflação, Desemprego e Taxas de Juros. Rio de Janeiro. Globo, 1985.

. Economia Heterodoxa X Economia Ortodoxa. Os Planos Econômicos Brasileiros. Porto Alegre. Ortiz, 1989.

PHILLIPS, A.W. The Relation Between Unemployment and the Change of Money Wage Rates in the United Kingdom, 1861/1957. Economica, v.25. N. 100, Nov. 1968.

STUART, C.E. Swedish Tax Rate, Labor Supply and Tax Revenues. Journal of Political Economy, 1981.

THE SCANDINAVIAN ECONOMIES. Estatisticas. Ny Adelgade, 5,4.

DK-1104. Copenhagen. Ed. Hilary Barnes, 1990.

WICKSELL, Knut. Professor Cassel's System of Economics. In: Lectures

on Political Economy. London, Routledge e Kegan Paul Ltda, 1951, v.1, p.219-57.

- The Critical Point in the Law of Decreasing Agricultural

Productivity, 1916. In: Selected Papers on Economic Theory. London. George Allen e Unwin Ltd., 1958, p.131-37.

On the Problem of Distribution, 1902. Op.cit.

- Interest and Prices. New York. Reprints of Economic

Ciassics. Augustus M. Kelley, Bookseller, 1965.

\section{ABSTRACT \\ THE SWEDISH ECONOMIC DEVELOPMENT: THE ROAD TO STATE INTERVENTION}

This paper, based on the Swedish Economy, shows that all countries that are heavily guided by the public sector to develop their economies tend to have a depression as a consequence. Sooner or later the artificial development based on the public sector has to be reverted with high costs in 
production and unemployment. The paper studies the origin, early stages, consolidation, the beginning of the decline, the decline itself and the difficult present situation of the Swedish welfare state. Inevitably, the Swedish people is going to pay a high price in production and unemployment in order to bring their economy back to equilibrium. However, this is only possible if Sweden first comes back to the domain of the market rules. 